\title{
Can the Late Heavy Bombardment concept be resuscitated?
}

\author{
ANDREW PARISI ${ }^{1}$, T.M. HARRISON ${ }^{1}$, CAMERON \\ MERCER $^{3}$, AND KIP HODGES ${ }^{2}$
}

${ }^{1}$ Dept. of Earth, Planetary \& Space, UCLA, Los Angeles, CA ${ }^{2}$ School of Earth \& Planetary Exploration, ASU, Tempe, AZ ${ }^{3}$ NASA Goddard Spaeflight Center, Greenbelt, MD

The concept of a Late Heavy Bombardment (LHB) of Moon at $\sim 3.9 \mathrm{Ga}$, based on geochemical arguments, was initially controversial but became widely accepted when ${ }^{40} \mathrm{Ar} /{ }^{39} \mathrm{Ar}$ step-heating analyses of Apollo samples appeared to yield $3.9 \mathrm{Ga}$ "plateau" ages. Recently, application of the "plateau age" model for dating complex impact melt rocks (not the simpler mineral systems for which the model was developed) has attracted criticism [1]. For impact melt rocks, degassing artifacts and the variation of Ar diffusivity in constituent phases frustrate attempts to extract robust impact age estimates from conventional ${ }^{40} \mathrm{Ar} /{ }^{39} \mathrm{Ar}$ incremental heating data alone. While it has been argued that highly clustered ages from multiple isotopic methods on individual lunar rocks provide confidence that interpreted impact ages are meaningful [2], the actual data backing up this assertion are sparse.

We are attempting to rectify this through SIMS U-Th-Pb dating of neoformed zircon, apatite, and merrillite in welldocumented lunar melt rocks 77115 and 73217 , previously found to contain three discrete melt domains ranging from 3.8 to $3.3 \mathrm{Ga}$ by ${ }^{40} \mathrm{Ar} /{ }^{39} \mathrm{Ar}$ laserprobe dating [3]. Replication of the existing ${ }^{40} \mathrm{Ar} /{ }^{39} \mathrm{Ar}$ laserprobe ages would provide the first evidence that multiple isotopic sytems can yield concordant ages of lunar melt rocks and increase our confidence in interpreted impact ages. But even so, a multichronometric analytical campaign conducted on many samples would be required to confirm the LHB hypothesis. Such efforts would be complicated by the fact that not all lunar melt rocks are likely to contain accessory minerals appropriate for such studies. Their presence depends on both the thermal state and chemistry of the melt. Most lunar rocks outside the Procellarum KREEP terrane are not capable of crystallizing accessory phases large enough for in situ chronologic investigation because high levels of $\mathrm{P}$ and $\mathrm{Zr}$ needed to stabilize magmatic phosphates and zircon. This imposes an inherent bias in using them to establish global impact chronologies. Nonetheless, it should be possible to constrain the ages of large, nearside, basin-forming impacts.

[1] Boehnke \& Harrison (2016) PNAS 113, 10802; [2] Bottke \& Norman (2017), AREPS 45, 619; [3] Mercer et al. (2015) Science Advances 1, 1 . 